\title{
Avian reovirus $L 2$ genome segment sequences and predicted structure/function of the encoded RNA-dependent RNA polymerase protein

\author{
Wanhong $\mathrm{Xu}^{1,2}$ and Kevin M Coombs*1,2
}

\begin{abstract}
Address: ${ }^{1}$ Department of Medical Microbiology and Infectious Diseases, University of Manitoba, Winnipeg, Manitoba R3E 0J9, Canada and ${ }_{2}^{2}$ Manitoba Centre for Proteomics and Systems Biology, 715 McDermot Avenue, Winnipeg, Manitoba R3E 3P4, Canada

Email: Wanhong Xu - wanhongxu@ hotmail.com; Kevin M Coombs* - kcoombs@ms.umanitoba.ca

* Corresponding author
\end{abstract}

Published: 17 December 2008

Virology Journal 2008, 5:153 doi:10.1 186/1743-422X-5-153

This article is available from: http://www.virologyj.com/content/5/I//53

(c) $2008 \mathrm{Xu}$ and Coombs; licensee BioMed Central Ltd.

This is an Open Access article distributed under the terms of the Creative Commons Attribution License (http://creativecommons.org/licenses/by/2.0), which permits unrestricted use, distribution, and reproduction in any medium, provided the original work is properly cited.

\begin{abstract}
Background: The orthoreoviruses are infectious agents that possess a genome comprised of 10 double-stranded RNA segments encased in two concentric protein capsids. Like virtually all RNA viruses, an RNA-dependent RNA polymerase (RdRp) enzyme is required for viral propagation. RdRp sequences have been determined for the prototype mammalian orthoreoviruses and for several other closely-related reoviruses, including aquareoviruses, but have not yet been reported for any avian orthoreoviruses.

Results: We determined the $\mathrm{L} 2$ genome segment nucleotide sequences, which encode the RdRp proteins, of two different avian reoviruses, strains ARVI38 and ARVI76 in order to define conserved and variable regions within reovirus RdRp proteins and to better delineate structure/ function of this important enzyme. The ARVI38 L2 genome segment was 3829 base pairs long, whereas the ARVI76 L2 segment was 3830 nucleotides long. Both segments were predicted to encode $\lambda B$ RdRp proteins 1259 amino acids in length. Alignments of these newly-determined ARV genome segments, and their corresponding proteins, were performed with all currently available homologous mammalian reovirus (MRV) and aquareovirus (AqRV) genome segment and protein sequences. There was $\sim 55 \%$ amino acid identity between $A R V \lambda B$ and MRV $\lambda 3$ proteins, making the RdRp protein the most highly conserved of currently known orthoreovirus proteins, and there was $\sim 28 \%$ identity between ARV $\lambda B$ and homologous MRV and AqRV RdRp proteins. Predictive structure/function mapping of identical and conserved residues within the known MRV $\lambda 3$ atomic structure indicated most identical amino acids and conservative substitutions were located near and within predicted catalytic domains and lining RdRp channels, whereas non-identical amino acids were generally located on the molecule's surfaces.
\end{abstract}

Conclusion: The ARV $\lambda B$ and MRV $\lambda 3$ proteins showed the highest ARV:MRV identity values ( $55 \%)$ amongst all currently known ARV and MRV proteins. This implies significant evolutionary constraints are placed on dsRNA RdRp molecules, particularly in regions comprising the canonical polymerase motifs and residues thought to interact directly with template and nascent mRNA. This may point the way to improved design of anti-viral agents specifically targeting this enzyme. 


\section{Background}

The avian reoviruses (ARVs) are members of the family Reoviridae, the only group of dsRNA viruses (out of seven dsRNA virus families) that infect mammals [1,2]. The ARVs are the prototypic members of syncytia-inducing, non-enveloped viruses within the Orthoreovirus genus. This genus is divided into 3 subgroups: non-syncytiainducing mammalian reovirus (MRV; subgroup 1 ; the prototype of the whole genus), avian reovirus and Nelson Bay virus (subgroup 2), and baboon reovirus (subgroup 3) [3]. In contrast to the MRV, which are rarely associated with human pathology $[2,4-6]$, the ARV are significant pathogens of poultry, and cause a variety of diseases, including infectious enteritis in turkeys [7], viral arthritis/ tenosynovitis [8], "pale bird" and runting-stunting syndromes [9], and gastroenteritis, hepatitis, myocarditis, and respiratory illness in chickens $[2,8,10]$.

Like MRV, ARV is a non-enveloped virus with 10 linear double-stranded RNA gene segments surrounded by a double concentric icosahedral capsid shell (inner shell [also called core] and outer shell) of 70-80 nm diameter $[11,12]$. The ARV genomic segments can be resolved into three size classes based on their electrophoretic mobilities, designated L (large), M (medium), and S (small) $[11,12]$. In total, the genomic composition includes 3 large segments (Ll, L2, L3), 3 medium sized segments (Ml, M2, M3), and 4 small segments (S1, S2, S3, S4). Nine of the segments are monocistronic and encode a single different protein [11-13] while S1 is tricistronic with partially overlapping open reading frames (ORFs) that encode for three proteins $[14,15]$. Although ARVs share many features with the prototypic MRVs, several notable differences exist including host range, pathogenicity, hemagglutination properties, and syncytium formation $[11,12,16-21]$.

Genomic coding differences also exist between MRV and ARV. For example, although the ARV and MRV S1 genome segments encode homologous receptor-binding proteins $[19,22,23]$, the ARV S1 genome segment encodes two additional ARV-specific gene products, one of which is responsible for ARV's unusual cell-cell fusion ability $[14,15,24]$, whereas the MRV S1 segment encodes only one additional protein [25]. In addition, available data $[12,26]$ suggest each of the homologous orthoreovirus $\lambda$ class proteins are encoded by different ARV and MRV Lclass genome segments. Differences in the functional properties of homologous ARV and MRV proteins have also been reported. For example, two non-homologous dsRNA-binding proteins (the ARV $\sigma$ A core protein and the MRV $\sigma 3$ major outer capsid protein) are predicted to regulate PKR activation $[27,28]$ while the ARV $\sigma$ A core protein displays nucleoside triphosphate phosphohydrolase (NTPase) activity [29], ascribed to the non-homologous
MRV $\mu 2$ [30] and $\lambda 1$ [31] core proteins. Based on these early comparative studies, it seems likely that additional analysis of ARV will continue to broaden our understanding of the Reoviridae family, possibly leading to the identification of novel features that impact on the distinct biological and pathogenic properties of ARV.

Recent advances have allowed sequence determinations of a growing number of virus isolates. Many ARV and MRV genome segment sequences have been reported. In addition, the complete genomic sequences of three prototype strains of MRV have been completed [32-34]. In contrast, sequence information from ARV isolates is more limited. While the entire complement of S-class genome segments (for example, [14,15,35-39]) and M-class genome segments (for example, $[40,41]$ ) have been determined for some ARV clones, and sequence information is available for some ARV L1 and L3 genome segments $[42,43]$, there is, at present, no sequence information for the ARV L2 genome segment. This segment is presumed to encode for the viral RNA-dependent RNA polymerase (RdRp) protein, an essential enzyme for RNA virus replication. Thus, we determined the genomic sequences of the ARV L2 genome segments from two different strains of ARV (ARV138 and ARV176) in order to expand the available ARV sequence database, determine sequences of the ARV RdRp protein, and to delineate conserved structure/ function features of this key viral-encoded enzyme.

\section{Methods \\ Cells and viruses}

Avian reovirus strain 138 (ARV138) and strain 176 (ARV176) are laboratory stocks. Virus clones were amplified in the continuous quail cell line QM5 in Medium 199 (Gibco) supplemented to contain $7.5 \%$ fetal calf serum (Hyclone), $2 \mathrm{mM}$ glutamine, $100 \mathrm{U} / \mathrm{ml}$ penicillin, $100 \mu \mathrm{g} /$ $\mathrm{ml}$ streptomycin, and $1 \mu \mathrm{g} / \mathrm{ml}$ amphotericin $\mathrm{B}$, essentially as previously described [44].

\section{Sequencing the $L 2$ genome segment}

Genomic dsRNA was extracted from amplified virus P2 stocks with phenol/chloroform [45]. The extracted dsRNA were resolved in 10\% SDS-PAGE and resolved L1, L2, and L3 segments separately excised. Individual segment gel bands were collected into microcentrifuge tubes, macerated, and incubated in 1-2 volumes of diffusion buffer (0.5 $\mathrm{M}$ ammonium acetate; $10 \mathrm{mM}$ magnesium acetate; 1 mM EDTA, $\mathrm{pH} 8.0 ; 0.1 \%$ SDS) at $50^{\circ} \mathrm{C}$ for 30 minutes. The macerated gel pieces were pelleted by centrifugation at $10,000 \times \mathrm{g}$ for $1 \mathrm{~min}$, supernatants were collected and dsRNA precipitated by ethanol. Each pellet was dried and resuspended in $\mathrm{dd}_{2} \mathrm{O}$ for 3' ligation-based RT-PCR. All primers used for ligation, RT-PCR, and sequencing were synthesized by Invitrogen. An anchor primer, P-5' CTTATTTATTTGCGAGATGGTTATCATTTTAATTATCTC- 
CATG 3'-Bio (5'-end phosphorylated and 3'-end biotinblocked) was ligated to the 3 ' end of each genome segment, using T4 RNA ligase according to the manufacturer's instructions (Promega Inc., Madison, USA). Ligated products were precipitated by mixing with $1 / 2$ volume of ( $30 \%$ PEG 8000 in $30 \mathrm{mM} \mathrm{MgCl}_{2}$ ), and centrifuged immediately at $10,000 \times \mathrm{g}$ for 30 minutes. The supernatants were removed and pellets were dried and dissolved in $\mathrm{ddH}_{2} \mathrm{O}$ for cDNA synthesis. Full-length cDNA copies of each L2 genome segment were synthesized using a primer (24-mer) complementary to the anchor primer by SuperScript ${ }^{\mathrm{TM}}$ II reverse transcriptase according to the manufacturer's instructions (Invitrogen). PCR amplification was performed using cDNA, a forward primer (i.e. primer used for RT), and a reverse primer, 5' ACCGAGGAGAGGgatgaataa 3', designed against highly conserved 3'-end nucleotide sequences of currently known consensus ARV L1 and L3 segment plus strands (shown in lower case) by Expand Long Template PCR System (Roche). PCR products used for DNA sequencing were gel purified using QIAquick ${ }^{\circledast}$ gel extraction kit according to the manufacturer's instructions (Qiagen).

DNA sequencing was performed in both directions by use of an ABI Prism BigDye Terminator v3.1 Cycle Sequencing Ready Reaction Kit (Applied Biosystems) and an Applied Biosystems Genetic Analyzer DNA Model 3100. The first two sequencing reactions were performed with the primers used for PCR amplification. Primers for subsequent reactions were designed from newly obtained sequences to completely sequence each full-length PCR product in both directions. Sequences nearer the ends of each segment were determined from PCR products that were amplified with a primer complementary to the anchor primer and an internal gene-specific primer. Sequences obtained from both directions were assembled and checked for accuracy with SeqMan ${ }^{\circledast}$ (Lasergene ${ }^{\varpi}$, Version 7.1.0; DNASTAR, Inc.).

\section{Sequence analyses}

Sequences were compiled and analyzed using the Lasergene $^{\varpi}$ software suite (Version 7.1.0; DNASTAR, Inc.) Pairwise sequence alignments were performed using the Wilbur-Lipman method [46] for highly divergent nucleotide sequences, the Martinez-NW method [47] for closely related nucleotide sequences, and the LipmanPearson method [48] for protein alignments in MegAlign ${ }^{\circledast}$ (Lasergene $^{\varpi}$ ). Multiple sequence alignments were performed using Clustal-W [49] and T-Coffee [50], and alignment adjustments were manually performed as needed in MegAlign ${ }^{\circledast}$. Amino acid alignment images were adjusted in Adobe Photoshop 7.0 (Adobe ${ }^{\varpi}$ ). Nucleotide compositions and protein molecular weights were calculated by DNA statistics and protein statistics, respectively, in EditSeq ${ }^{\varpi}$ (Lasergene $\left.{ }^{\circledast}\right)$. Phylogenetic trees were constructed using Neighbor-Joining and tested with 1000 bootstrap replicates in MEGA version 4 [51].

\section{3-D structural analyses}

Molecular graphics coordinates of the mammalian reovirus (MRV) $\lambda 3$ crystal structure (PDB \# 1MUK; [52]), were manipulated with the UCSF Chimera package from the Resource for Biocomputing, Visualization, and Informatics at the University of California, San Francisco ([53]; supported by NIH P41 RR-01081). Resulting images were imported into Adobe Photoshop and assembled with Adobe Illustrator (Adobe).

\section{Results}

The sequences of genes that encode the RdRp protein have been determined for a number of members of the Reoviridae family of viruses (Table 1 ). However, this information was lacking for members of the avian orthoreovirus subgroup. We determined the sequences of two different strains' ARV L2 genome segments. The L2 genome segments of ARV138 and ARV176 were determined to be 3829 (GeneBank accession no. EU707935) and 3830 (GeneBank accession no. EU707936) nucleotides long, respectively (Table 2 ). The one-nucleotide length difference is attributed to the 5'-end of the non-translated region of the plus-strand, where ARV138 L2 contains a one-base deletion relative to ARV176 L2. No additional deletions or insertions were found elsewhere in the alignment. The nucleotide identity between ARV138 and ARV176 L2 genome segments is $85 \%$ (Table 3). BLAST searches indicated the ARV L2 genome segments were most similar to the mammalian reovirus (MRV) and aquareovirus (AqRV) L1 genome segments, which encode the RNA-dependent RNA polymerase [54,55]. Pairwise sequence comparisons between both of these newlydetermined ARV genome segments and all currently available homologous MRV and AqRV L1 genome segments (see Table 1) showed a range of nucleotide and protein identity values. Preliminary comparative studies of all currently available AqRV L-class genome segments indicated that the grass carp reovirus (GCRV) and chum salmon reovirus (CSRV) L genes were the most distantly related amongst the AqRV (data not shown). Thus, although all currently available ARV, MRV, and AqRV L-class genome segments were aligned and compared in subsequent analyses, we limited presentation in subsequent tables and figures to these few most-distant clones for clarity. In addition, preliminary attempts to align the ARV138 and ARV176 L2 genome segments with homologous genes in other Reoviridae genera (ie. the Fijivirus Nilaparvata lugens, the Dinovernavirus Aedes pseudoscutellaris, the Coltivirus Eyach virus, the Orbivirus St. Croix River virus, the Seadornavirus Kadipiro virus, the Mimoreovirus Micromonas pusilla reovirus, and the currently unclassified virus Operophtera brumata reovirus) resulted in much lower identity 
Table I: Nucleotide sequences used in this study

\begin{tabular}{|c|c|}
\hline Strain & GenBank Accession Number \\
\hline \multicolumn{2}{|l|}{$A R V^{a}$} \\
\hline 138 & EU707935 \\
\hline 176 & EU707936 \\
\hline \multicolumn{2}{|l|}{$M R V^{b}$} \\
\hline TIL & NC 004271 \\
\hline T2 & NC 004272 \\
\hline T3D & EF494435 \\
\hline $\mathrm{T} 4 \mathrm{~N}$ & AF368033 \\
\hline BYDI & DQ664184 \\
\hline SC-A & DQ997719 \\
\hline \multicolumn{2}{|l|}{$A q R V c$} \\
\hline GCRV & AF260512 \\
\hline $\mathrm{GCHV}$ & AF284502 \\
\hline GSRV & NC 005167 \\
\hline AGCRV & $\underline{N C} 010585$ \\
\hline CSRV & NC 007583 \\
\hline ASRV & EF434978 \\
\hline
\end{tabular}

a $A R V$, avian reovirus.

b MRV, mammalian reovirus. TIL, type ILang; T2J, type 2 Jones; T3D, type 3 Dearing; T4N, type 4 Ndelle.

cAqRV, Aquareovirus. GCRV, Grass carp reovirus; GCHV, Grass carp hemorrhagic virus; GSRV, Golden shiner reovirus; AGCRV, American grass carp reovirus; CSRV, Chum salmon reovirus; ASRV, Atlantic salmon reovirus.

values and significant gaps (data not shown); thus, these other more-distant genera were not included in subsequent analyses. Pairwise nucleotide sequence comparisons between ARV L2 and homologous MRV genome segments showed identities of $\sim 55 \%$, and pairwise nucleotide sequence comparisons of ARV L2 with AqRV homologues revealed $\sim 48 \%$ identity (Table 3 ).

The predicted open reading frames for both ARV L2 segments were determined to be nucleotides $14-3790$ for ARV138 L2 and 15-3791 for ARV176 L2, resulting in deduced $\lambda B$ proteins of 1259 residues (Table 2). The calculated molecular weights for ARV138 $\lambda \mathrm{B}$ and ARV176 $\lambda \mathrm{B}$ are $\sim 140 \mathrm{kDa}$ each (Table 2). The amino acid identity between the two ARV $\lambda B$ proteins is $97.5 \%$, with no insertions or deletions relative to one another. ARV protein $\lambda B$ is the only ARV protein whose sequence has not been reported previously. Thus, completion of the L2 sequence in this study has allowed us to assign its function at the sequence level. Amino acid alignments of ARV $\lambda B$, MRV $\lambda 3$, and AqRV VP2 proteins revealed several regions of high amino acid identity (Fig. 1), many of which correspond to previously identified polymerase domains [56]. A large number of amino acids were completely conserved across all 14 currently known ARV, MRV, and AqRV RdRp protein sequences (Fig. 1, closed circles). Amino acid identities between ARV $\lambda \mathrm{B}$ and homologous MRV $\lambda 3$ or AqRV VP2 are $\sim 55 \%$ and $\sim 42 \%$, respectively (Table 3 ), suggesting the ARV and MRV are more closely related to each other than either are to AqRV (also seen in phylogenetic analysis - Fig. 2), reflecting that ARV and MRV belong to different species in the Orthoreovirus genus [36] whereas AqRV are members of the different Aquareovirus genus in the Reoviridae family. Window-averaged analysis of ARV $\lambda B$ and MRV $\lambda 3$ protein identities (Fig. 3, dashed lines) revealed several regions of high amino acid identity. The highest identity scores, with window-averaged identity values $>90 \%$, were located within canonical polymerase regions, including "fingers" domains (MRV residues 452 - 467 and 514 - 530) "fingers"/"palm" interface domains (MRV residues 542 - 571 and 673 - 699), "palm" domains (MRV residues 725 - 738, which includes the GDD motif, which is common to all viral RNA-dependent RNA polymerases [57-59]), "thumb" domains (MRV residues $864-878$ ), and an "undefined" domain (MRV residues 881 - 896). Addition of the AqRV VP2 protein to the above analyses provided additional information about potentially important conserved domains. Clustal-W (Fig. 1) and T-Coffee (data not shown) alignments identified 359 amino acid residues that were identical in the 6 aligned sequences (overall average identity $=28.3 \%$ Fig. 3 , horizontal solid line]) . There were numerous window-averaged regions of very low conservation, with most attributed to AqRV regions that were poorly conserved compared to corresponding $\mathrm{ARV} / \mathrm{MRV}$ regions, a feature also noted in MRV:AqRV comparisons [60]. Three regions showed higher-thanaverage conservation in the ARV:MRV:AqRV alignments, with window-averaged identity values $>75 \%$, suggesting these polymerase regions (ARV residues $\mathrm{G}_{516} \mathrm{LRNQV}$ QRRPRTIMP $_{530}, \mathrm{H}_{542}$ TLS/CADYINYHMNLSTTSGSAV ${ }_{563}$, and $\mathrm{T}_{677}$ TTFPSGSTATSTEHTANNSTM $_{698}$, that correspond to MRV residues $\mathrm{G}_{516}$ LRNQVQRRPRSIMP $_{530}, \mathrm{H}_{542}$ TLTAD YINYHMNLSTTSGSAV ${ }_{563}$, and $\mathrm{T}_{677}$ TTFPSGSTATSTEHTA NNSTM $_{698}$, respectively) contain important structural/ functional domains. The GDD motif was located within a region of slightly lower window-averaged scores $(\sim 60 \%)$, but in a sequence (in ARV) $I_{724}$ QxxYVCQGDDG $_{735}$ that, 
Table 2: Genome-segment lengths, non-translated regions, and encoded proteins of ARVI38 and ARVI76

\begin{tabular}{|c|c|c|c|c|c|c|c|c|}
\hline \multirow[t]{2}{*}{ Genome segment } & \multirow[t]{2}{*}{ Base pairsa } & \multirow{2}{*}{$\begin{array}{l}5^{\prime} \text { NTR'b } \\
\text { (no. of bases) }\end{array}$} & \multirow{2}{*}{$\begin{array}{l}\text { 3' NTR } \\
\text { (no. of bases) }\end{array}$} & \multirow[t]{2}{*}{ ORFc } & \multirow[t]{2}{*}{ Codons $^{d}$} & \multirow[t]{2}{*}{ Protein } & \multicolumn{2}{|c|}{ Molecular weight $(\mathrm{kDa}) \mathrm{e}$} \\
\hline & & & & & & & ARVI38 & ARVI76 \\
\hline$L^{f} f$ & 3958 & 20 & 56 & $21-3899$ & 1293 & $\lambda \mathrm{A}$ & 142.3 & 142.2 \\
\hline L2 & $3829 g$ & $13^{\mathrm{h}}$ & 36 & $14-3790^{i}$ & 1259 & $\lambda B$ & 139.7 & 139.8 \\
\hline $\mathrm{L}^{f}$ & 3907 & 12 & 37 & $13-3867$ & 1285 & $\lambda C$ & 141.9 & 142.2 \\
\hline MI & 2283 & 12 & 72 & $13-2208$ & 732 & $\mu \mathrm{A}$ & 82.0 & 82.2 \\
\hline M2 & 2158 & 29 & 98 & $30-2057$ & 676 & $\mu \mathrm{B}$ & 73.1 & 73.3 \\
\hline M3 & 1996 & 24 & 64 & $25-1929$ & 635 & $\mu C$ & 70.9 & 70.8 \\
\hline \multirow[t]{3}{*}{ SI } & 1643 & 24 & 33 & $25-318$ & 98 & plo & 10.3 & 10.3 \\
\hline & & & & $293-730$ & 146 & $\mathrm{pl}$ & 16.9 & 16.9 \\
\hline & & & & $630-1607$ & 326 & $\sigma \mathrm{C}$ & 34.9 & 34.8 \\
\hline S2 & 1324 & 15 & 58 & $16-1263$ & 416 & $\sigma \mathrm{A}$ & 46.1 & 46.1 \\
\hline S3 & 1202 & 30 & 68 & $3|-| 13 \mid$ & 367 & $\sigma \mathrm{B}$ & 40.9 & 40.9 \\
\hline S4 & 1192 & 23 & 65 & $24-1124$ & 367 & $\sigma N S$ & 40.5 & 40.6 \\
\hline Total & $23492^{j}$ & & & & & & & \\
\hline
\end{tabular}

a Total nucleotides on each strand.

bNTR, non-translated region.

cNucleotide positions indicated for starting and ending codons.

dTotal number of amino acids in deduced protein.

eMolecular weight calculated from deduced protein and rounded to closest $0.1 \mathrm{kDa}$.

fUnpublished.

83830 for ARVI76.

h|4 for ARVI 76

i|5-379I for ARVI76.

i 23,493 for ARVI76.

Table 3: Percent identities of the ARV L2 genome segments and homologous encoded proteins of MRV and Aquareoviruses ${ }^{\mathrm{a}}$

\begin{tabular}{|c|c|c|c|c|c|c|c|c|}
\hline Strain & ARVI38 & ARVI76 & TIL & T2J & $\mathrm{T} 3 \mathrm{D}$ & $\mathrm{T} 4 \mathrm{~N}$ & GCRV & CSRV \\
\hline ARVI38 & & 98 & 55 & 55 & 55 & 55 & 42 & $4 I$ \\
\hline ARVI76 & 85 & & 55 & 55 & 55 & 55 & 42 & 41 \\
\hline TIL & 55 & 55 & & 92 & 99 & 97 & 42 & 41 \\
\hline T2J & 55 & 55 & 75 & & 92 & 91 & 42 & 40 \\
\hline T3D & 55 & 55 & 96 & 76 & & 98 & 42 & 41 \\
\hline $\mathrm{T} 4 \mathrm{~N}$ & 56 & 56 & 89 & 75 & 90 & & 42 & 41 \\
\hline GCRV & 49 & 49 & 48 & 47 & 48 & 47 & & 58 \\
\hline CSRV & 47 & 47 & 47 & 46 & 47 & 47 & 59 & \\
\hline
\end{tabular}

a Percent amino acid identities indicated in upper triangle; percent nucleotide identities are in lower triangle, in bold. 


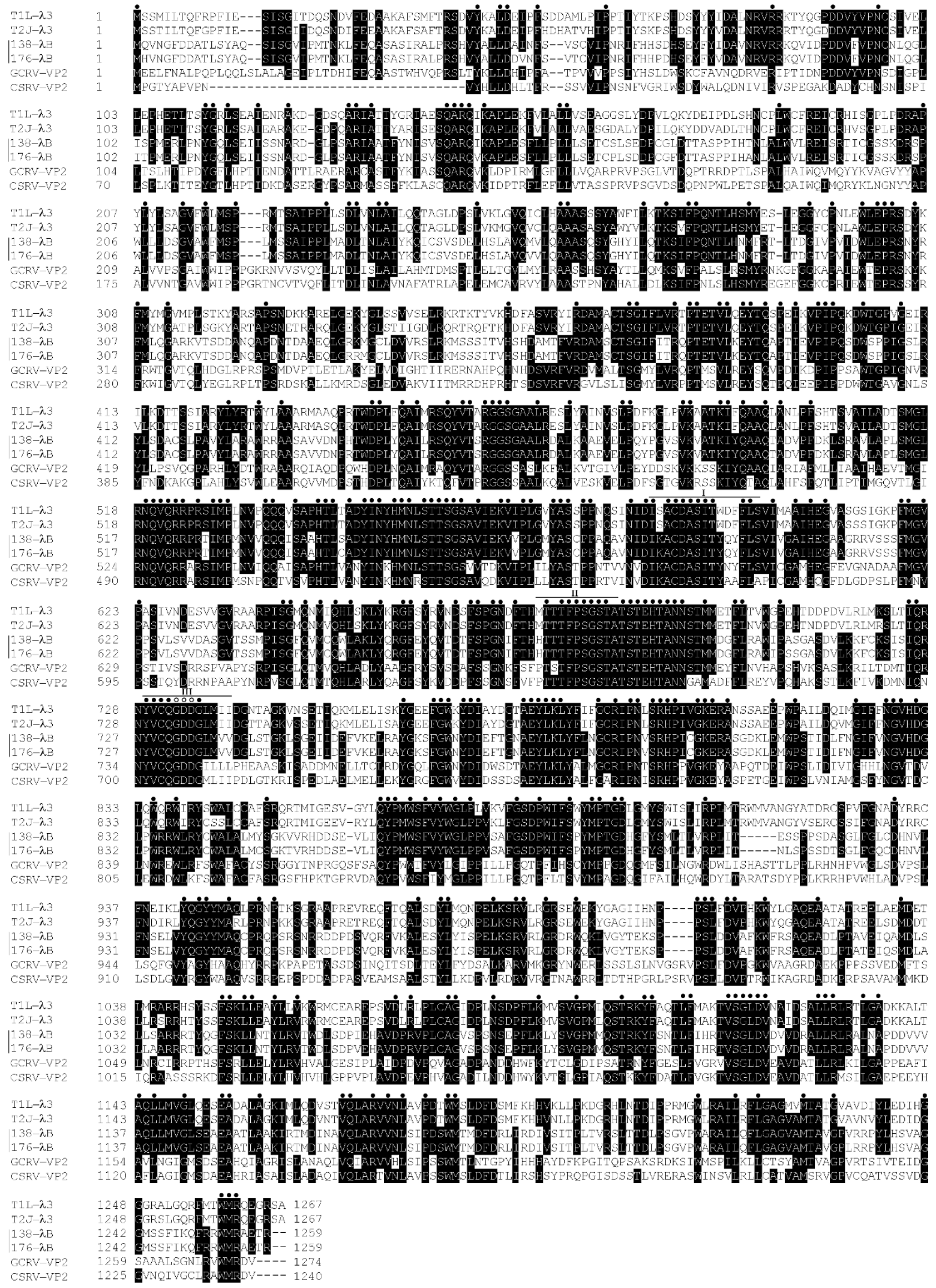

Figure I (see legend on next page) 
Figure I (see previous page)

Alignment of the deduced ARVI38 and ARVI 76 B B amino acid sequences. All I 4 currently available homologous ARV $\lambda B, M R V \lambda 3$, and AqRV VP2 proteins (determined for each clone shown in Table I) were aligned, both by T-Coffee [50] (data not shown) and by Clustal-W [49], with only minor differences in the alignments created by different gap penalties (data not shown). Only the two most-distant ARV, MRV, and AqRV sequences (see text for details) are shown for clarity. Clones are: MRV - TIL (GenBank No. NC 00427I) and T2J (GenBank No. NC 004272); ARV - ARVI 38 (GenBank No. EU707935) and ARVI 76 (GenBank No. EU707936); AqRV - Grass Carp reovirus (GCRV) (GenBank No. AF2605I2) and Chum Salmon reovirus (CSRV) (GenBank No. NC 007583). Amino acid residues that are identical in at least four of the sequences are indicated by black background shading. The single letter amino acid code is used. Previously identified polymerase domains (labeled I - III) [56] are indicated with solid horizontal lines above the sequences. Amino acid residues that are completely conserved in all 14 sequences are indicated by closed circles, and the GDD motif found in all polymerases is indicated by open circles, shown above the sequences.

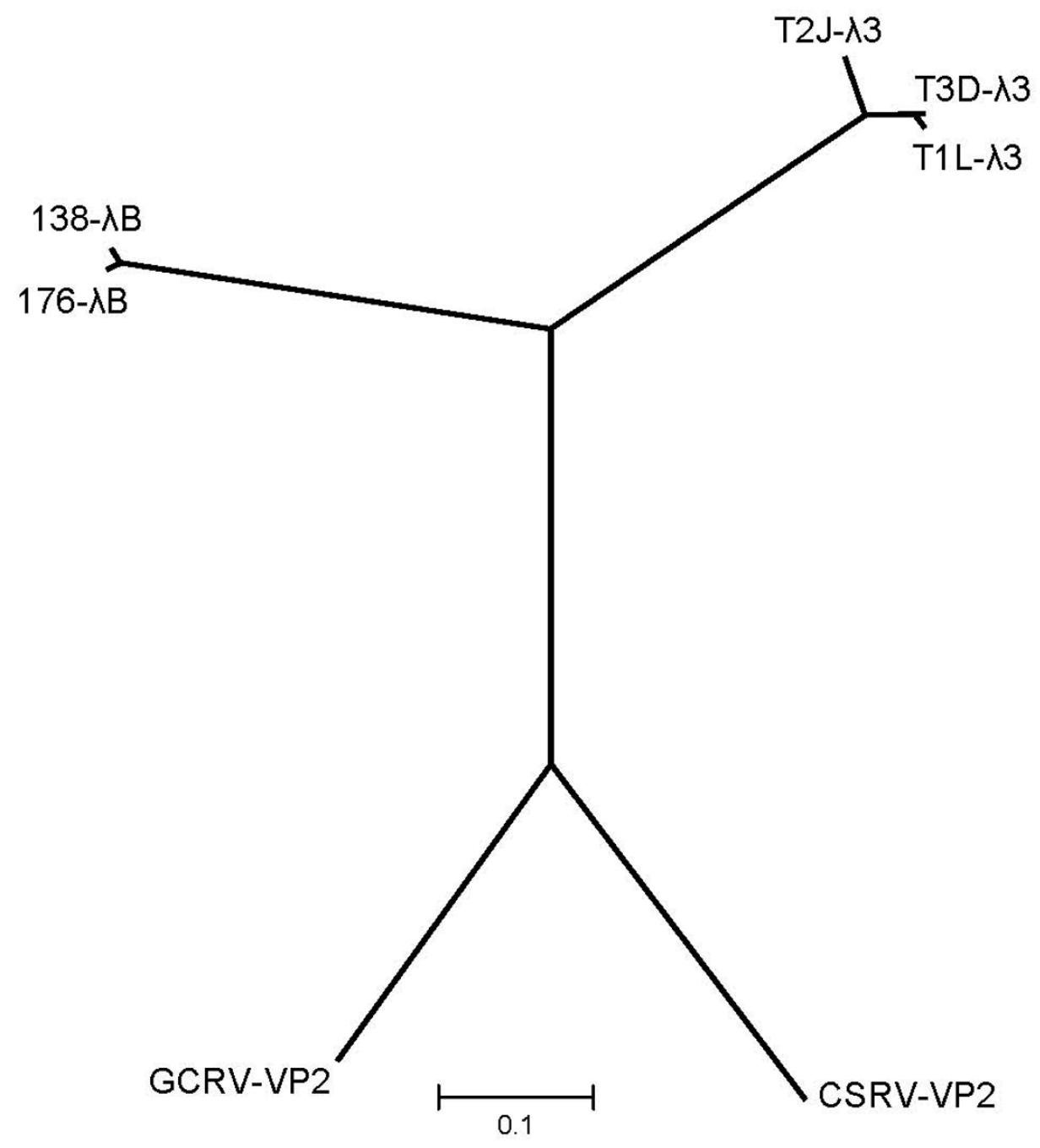

Figure 2

Phylogenetic tree analyses of the prototype ARV L2 genome segments and homologous genes in other reoviruses. Abbreviations are as defined in the legend to Fig. I. Lines are proportional in length to nucleotide substitution. Alignments were performed by Neighbor-Joining and tested with 1000 bootstrap replicates in MEGA version 4 [5I]. 


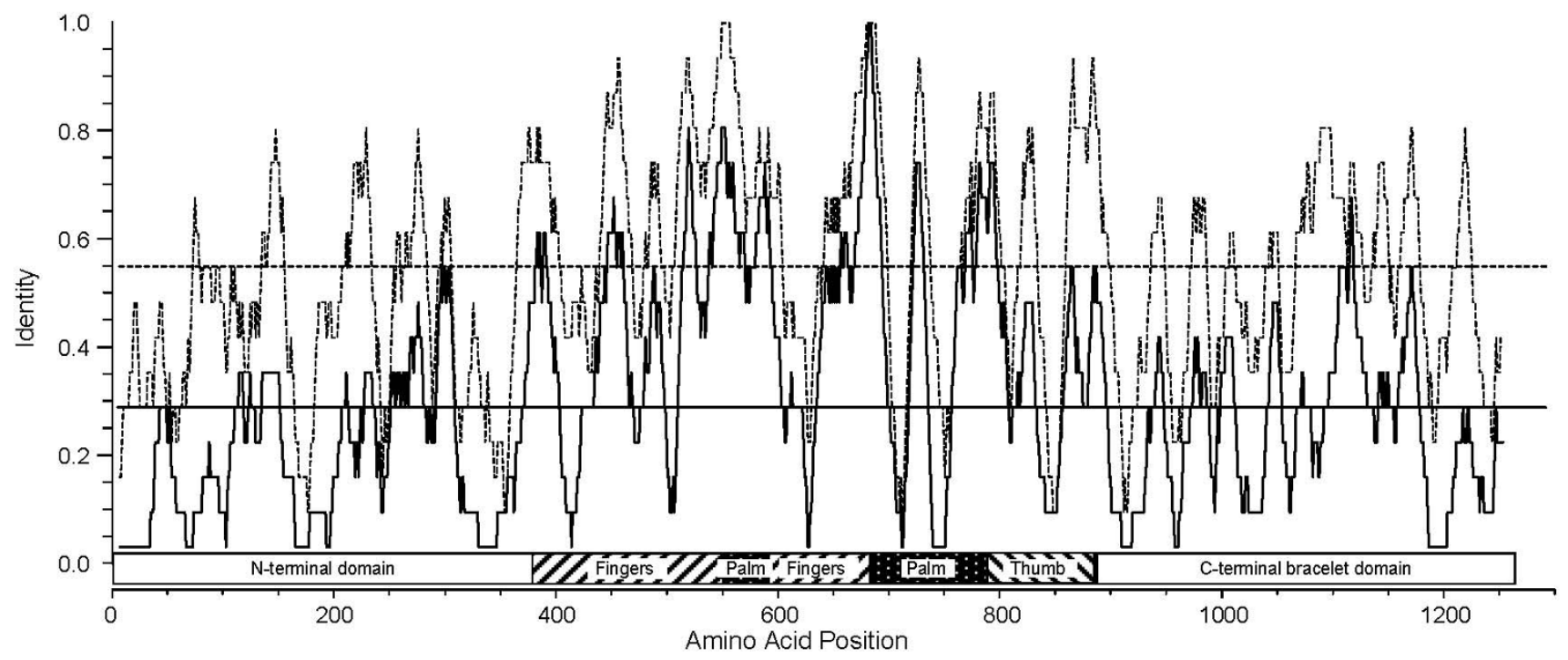

Figure 3

Window-averaged scores for sequence identity among the ARV $\lambda$ B, AqRV VP2, and MRV $\lambda 3$ RNA-dependent RNA polymerase proteins. To provide consistent weighting to the averaged scores, only the two most-distant clones from each of the three groups (ARV: ARVI 38 and ARVI76; AqRV: GCRV and CSRV; MRV: TIL and T2J - see text for details) were used. Identity scores averaged over running windows of $I 5$ amino acids and centered at consecutive amino acid positions are shown for ARV:MRV comparisons (dashed lines) and ARV:MRV:AqRV comparisons (solid line). The global identity scores for each of the compared sequence sets are indicated by the horizontal lines. Previously-identified enzymatic motifs are indicated with boxes below the plots.

apart from the residues at positions 726 and 727 , were completely conserved in all 14 currently-available ARV, MRV, and AqRV RdRp sequences. In addition to the 359 identical residues found in all 6 sequences discussed above, blossum 50 weighting alignments indicated that an additional 206 positions contained either identical amino acid residues or conservative substitutions in at least 4 of the 6 aligned sequences.

\section{Discussion}

The atomic structure of few ARV proteins have been reported [61], and such high-resolution structures are not known for any $\lambda$-class ARV proteins. By contrast, atomic structures are known for most MRV proteins, including the RdRp [52]. Comparative sequence analyses described in this report have indicated that ARV and MRV RdRp proteins share $\sim 55 \%$ amino acid identity, ARV and AqRV RdRp proteins share $\sim 42 \%$ identity, and that only 359 ( $28 \%$ ) amino acids are completely conserved (identical) when ARV138, ARV176, MRV T1L, MRV T2J, AqRV CSRV, and AqRV GCRV are aligned (Fig. 1). Thus, to gain structure/function information about this key viral-encoded enzyme, ARV, MRV, and AqRV identical amino acids, conservative substitutions, and non-conservative substitutions were modeled in the MRV $\lambda 3$ crystal structure (Fig. 4). This comparative analysis indicated that most non- conserved amino acids were located on the surfaces of the protein exposed to the core interior and in the $\mathrm{N}$-terminal and C-terminal bracelet domains, whereas most identical amino acids and conservative substitutions were located within canonical fingers, palm, and thumb polymerase motifs, particularly those lining channels used by template and nascent RNA during transcription (Fig. 4). Similar observations had been reported from MRV:AqRV comparisons [60] and our results support and extend these earlier observations. As was previously reported from MRV:AqRV comparisons [60], conserved residues surround the GDD motif and additional residues shown to be important for a variety of polymerase functions are also conserved, including $\operatorname{Arg}_{522}, \mathrm{Arg}_{523}, \mathrm{Arg}_{525}, \mathrm{Ala}_{587}$ (which are needed to properly position the incoming NTP triphosphate), $\mathrm{Ile}_{527}$ and $\mathrm{PrO}_{529}$ (needed to help position template nucleosides), $\operatorname{Thr}_{557}, \operatorname{Ser}_{558}, \mathrm{Gly}_{559}, \operatorname{Ser}_{560}$, and $\mathrm{Val}_{562}$ (portions of a loop that maintains priming NTP), and $\mathrm{Asp}_{589}, \mathrm{Ser}_{681}$, and $\mathrm{Gln}_{731}$ (specifies ribonucleotides). Each of these residues is located one amino acid more Nterminal in the MRV sequence (ie. ARV $\operatorname{Arg}_{522}=\mathrm{MRV}$ $\operatorname{Arg}_{523}$ and all (as well as numerous others) are completely conserved in all 14 currently available ARV, MRV, and AqRV RdRp sequences (Fig. 1, indicated by closed circles). In addition, our comparative analyses indicated many identical amino acids and conservative substitutions were 
A

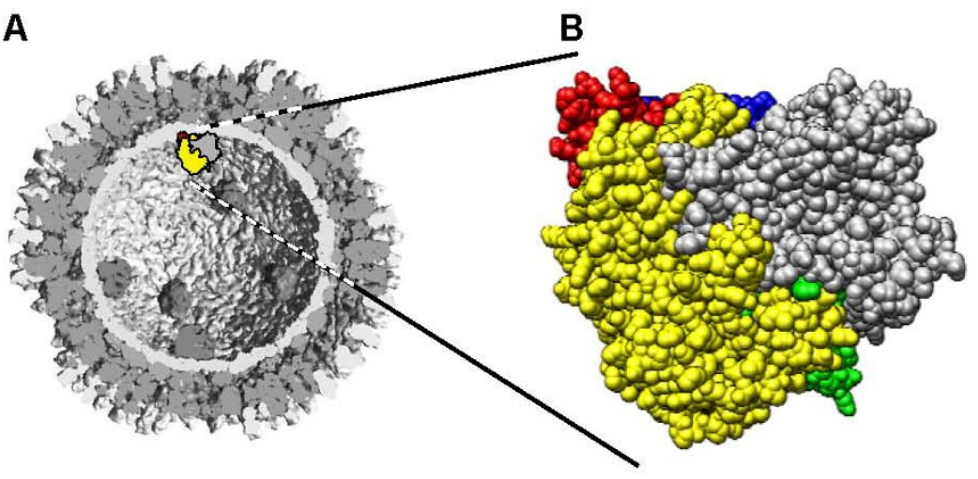

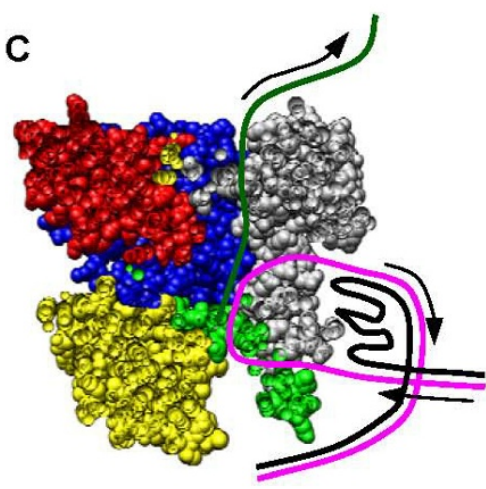

F

E

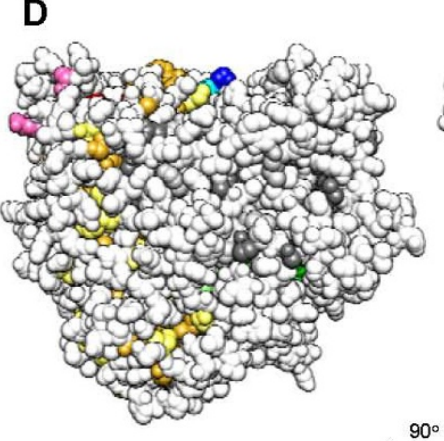

$90^{\circ}$

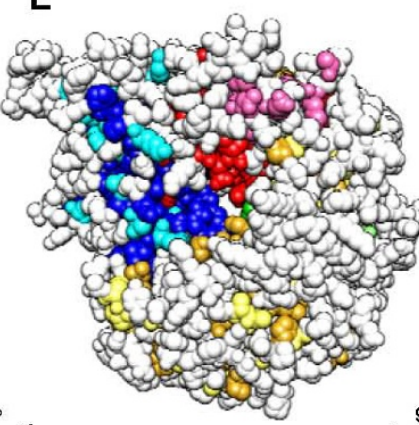

$\underbrace{90^{\circ}}$

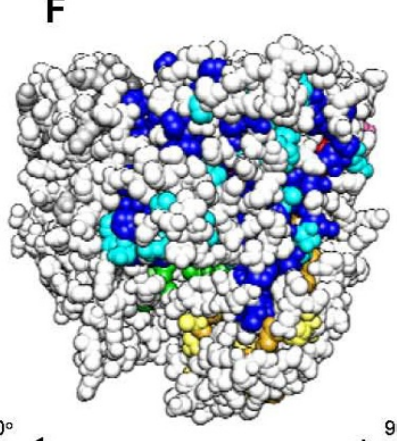

$90^{\circ}$

G

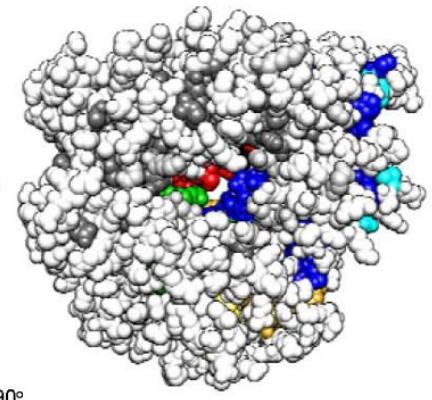

H

I
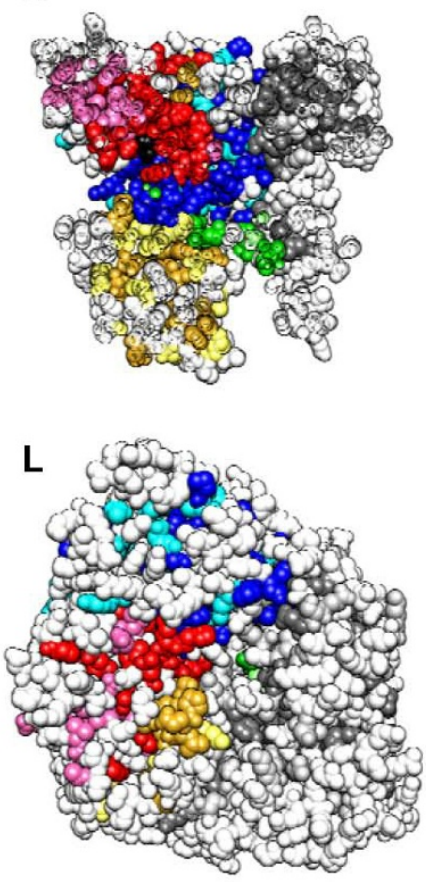

M
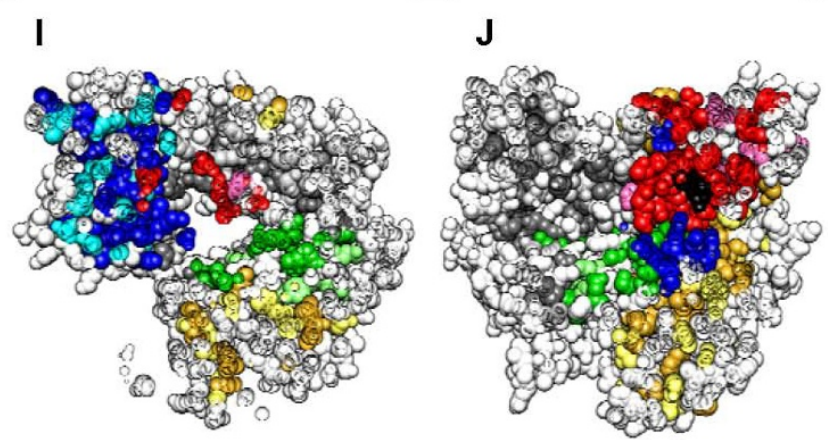

K
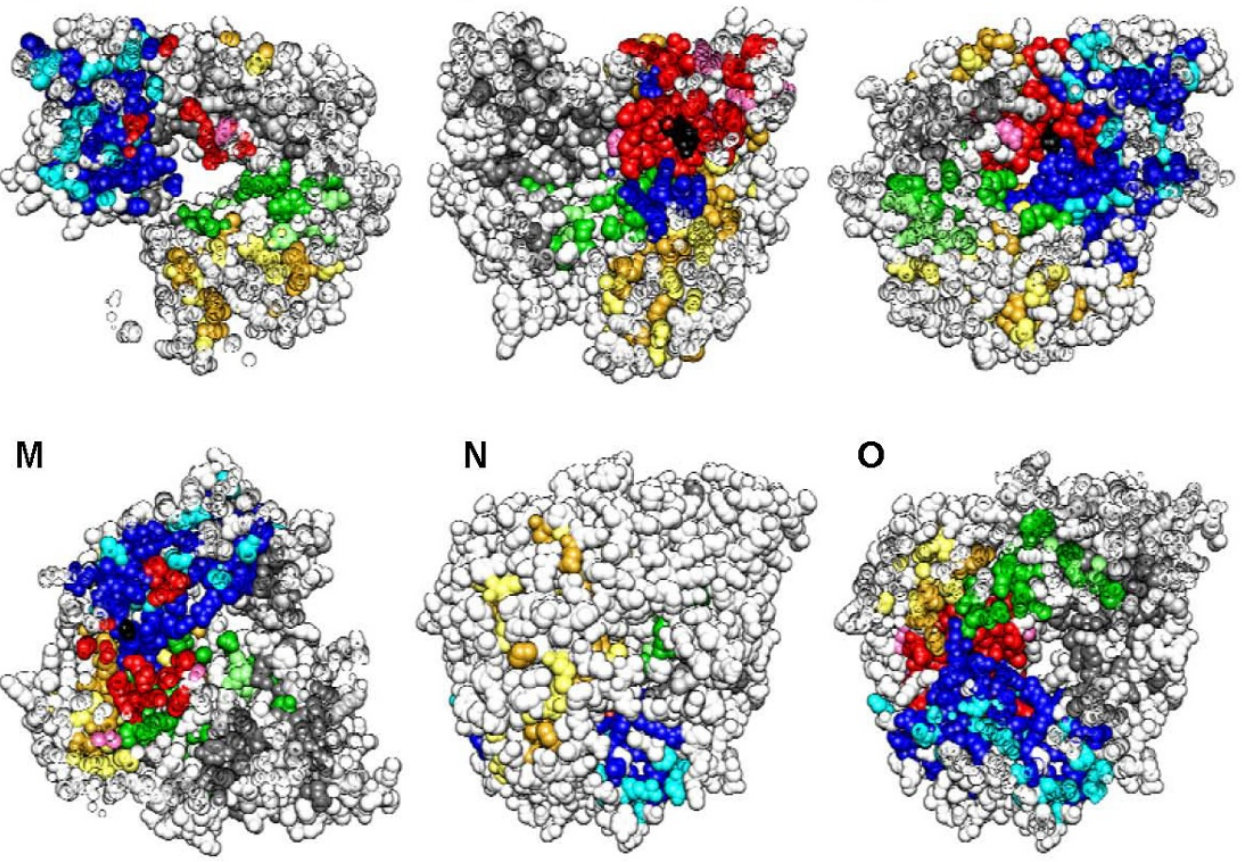

Figure 4 (see legend on next page) 
Figure 4 (see previous page)

Localization of conserved, non-conserved, and identical amino acids in ARV, MRV, and AqRV RdRp proteins. The MRV $\lambda 3$ crystal structure (PDB \# IMUK [52]) was manipulated with Chimera [53]. A, Low-resolution, cutaway model of the reovirus core structure (modified from [26] with permission). B, Blow-up of indicated $\lambda 3$ molecule in 'A', and C, cut-away of "B" with presumptive paths of genomic (+) RNA (black line), template genomic (-) RNA (magenta line) and nascent mRNA (dark green line) shown (adapted from and as described in [62]); Specific motifs in 'B' - 'O' are color-coded, with $\mathrm{N}$-terminal region in yellow, C-terminal "bracelet" in grey, and canonical polymerase "fingers", "palm", and "thumb" depicted in blue, red, and green, respectively. D, Same as 'B', but in "D" - "O", amino acids that are identical in all 6 ARV, MRV, and AqRV sequences (see Fig. I) are shown in darker versions of each motif color (goldenrod, dim grey, blue, red, and green, respectively), amino acids that represent conservative substitutions (as determined by Blossum50 matrix) are shown in lighter versions of each motif color (yellow, medium grey, cyan, hotpink, and light green, respectively), and non-conserved amino acids are shown in white. The canonical GDD motif is depicted in black. D - G, represent successive $90^{\circ}$ rotations counter-clockwise around vertical axis, of entire RdRp protein, to correspond to front (as depicted in "A"), left side, back, and right side. $\mathbf{H}-\mathbf{K}$, represent same views as "D - G", respectively, but with the front approximate half of each view removed. $\mathbf{L}$ and $\mathbf{N}$, represent top and bottom view, respectively, of RdRp molecule. $\mathbf{M}$, represents top view, after upper approximately $40 \%$ of view removed, and $\mathbf{O}$, represents bottom view, after lower approximately half of view removed. The top surface depicted in "L" is believed to interact with the $\lambda$-class core shell protein.

located on the surface of the protein that is predicted to interact with the core shell [62]. This might imply that conserved domains are needed to help tether the RdRp to the underside of the core shell. This hypothesis could be tested by extending such ARV:MRV:AqRV sequence comparisons to the other core proteins.

In conclusion, we report the first sequence analysis of the avian reovirus RdRp gene and protein. The ARV $\lambda B$ and MRV $\lambda 3$ proteins showed the highest ARV:MRV identity values ( $\sim 5 \%)$ amongst currently known ARV and MRV proteins, suggesting significant evolutionary constraints are placed on dsRNA RdRp molecules, particularly in regions comprising the canonical polymerase motifs and residues thought to interact directly with template and nascent mRNA.

\section{Competing interests}

The authors declare that they have no competing interests.

\section{Authors' contributions}

WX performed the experiments and analyses and WX and KC wrote the manuscript.

\section{Acknowledgements}

We thank members of our laboratory for critical reviews of this manuscript and Kolawole Opanubi for expert technical assistance. This research was supported by grant FRN-I I 630 from the Canadian Institutes of Health Research.

\section{References}

I. Mertens P: The dsRNA viruses. Virus Research 2004, 101:3-13.

2. Schiff LA, Nibert ML, Tyler KL: Orthoreoviruses and their replication. In Fields Virology Edited by: Knipe DM, Howley PM. Philadelphia: Lippincott Williams \& Wilkins; 2007: I853-1915.

3. Chappell JD, Duncan R, Mertens PPC, Dermody TS: "Genus Orthoreovirus". In Virus Taxonomy Eighth Report of the International Committee on Taxonomy of Viruses Edited by: Fauquet CM, Mayo MA, Maniloff J, Desselberger U, Ball LA. San Diego, CA: Elsevier Inc; 2005.
4. Johansson PJ, Sveger T, Ahlfors K, Ekstrand J, Svensson L: Reovirus type I associated with meningitis. Scand J Infect Dis 1996, 28:117-120.

5. Hermann L, Embree J, Hazelton P, Wells B, Coombs K: Reovirus type 2 isolated from cerebrospinal fluid. Ped Infect Dis J 2004, 23:373-375

6. Tyler KL, Barton ES, Ibach ML, Robinson C, Campbell JA, O'Donnell $S M$, et al.: Isolation and molecular characterization of a novel type 3 reovirus from a child with meningitis. J Infect Dis 2004, 189:1664-1675.

7. Gershowitz A, Wooley RW: Characterization of two reoviruses isolated from turkeys with infectious enteritis. Avian Dis 1973, 17:406-4|4.

8. Olson NO: "Reovirus infections". In Diseases of poultry Edited by: Hofstad MS. Ames, lowa: lowa State University Press; 1978.

9. Kouwenhoven B, Vertommen M, Eck JHv: Runting and leg weakness in broilers: involvement of infectious factors. Vet Sci Commun 1978, 2:253-259.

10. Rosenberger JK, Olson NO: "Reovirus infections". In Diseases of poultry Edited by: Calnek BW, Burnes MJ, Beard CW, Reid WM, Yoder HW. Ames, lowa: lowa State University Press; 1991.

II. Spandidos DA, Graham AF: Physical and chemical characterization of an avian reovirus. J Virol 1976, 19:968-976.

12. Benavente J, Martinez-Costas J: Avian reovirus: Structure and biology. Virus Research 2007, I 23:105-II9.

13. Gouvea VS, Schnitzer TJ: Polymorphism of the genomic RNAs among the avian reoviruses. J Gen Virol 1982, 6 I (Pt I):87-9I.

14. Bodelon G, Labrada L, Martinez-Costas J, Benavente J: The avian reovirus genome segment $S I$ is a functionally tricistronic gene that expresses one structural and two nonstructural proteins in infected cells. Virology 200I, 290: $181-191$.

15. Shmulevitz M, Yameen Z, Dawe S, Shou J, O'Hara D, Holmes I, et al: Sequential partially overlapping gene arrangement in the tricistronic SI genome segments of avian reovirus and $\mathrm{Nel}$ son Bay reovirus: implications for translation initiation. J Virol 2002, 76:609-618.

16. Schnitzer TJ: Protein coding assignment of the $\mathbf{S}$ genes of the avian reovirus SI I 33. Virology 1985, I4I:167-170.

17. Ni Y, Ramig RF: Characterization of avian reovirus-induced cell fusion: the role of viral structural proteins. Virology 1993 , 194:705-7|4

18. Theophilos MB, Huang JA, Holmes IH: Avian reovirus sigma C protein contains a putative fusion sequence and induces fusion when expressed in mammalian cells. Virology 1995, 208:678-684.

19. Martinez-Costas ], Grande A, Varela R, Garcia-Martinez C, Benavente J: Protein architecture of avian reovirus S I 133 and identification of the cell attachment protein. J Virol 1997, 71:59-64.

20. Jones RC: Avian reovirus infections. Rev Sci Tech 2000 19:6|4-625. 
21. Zhang X, Tang J, Walker SB, O'Hara D, Nibert ML, Duncan R, et al.: Structure of avian orthoreovirus virion by electron cryomicroscopy and image reconstruction. Virology 2005, 343:25-35.

22. Weiner $\mathrm{HL}$, Ault $\mathrm{KA}$, Fields $\mathrm{BN}$ : Interaction of reovirus with cell surface receptors. I. Murine and human lymphocytes have a receptor for the hemagglutinin of reovirus type 3 . J Immunol | 980, I 24:2|43-2|48.

23. Grande A, Costas C, Benavente J: Subunit composition and conformational stability of the oligomeric form of the avian reovirus cell-attachment protein sigmaC. J Gen Virol 2002, 83:131-139.

24. Shmulevitz M, Duncan R: A new class of fusion-associated small transmembrane (FAST) proteins encoded by the non-enveloped fusogenic reoviruses. EMBO J 2000, 19:902-912.

25. Munemitsu SM, Atwater JA, Samuel CE: Biosynthesis of reovirusspecified polypeptides. Molecular cDNA cloning and nucleotide sequence of the reovirus serotype I Lang strain bicistronic sl mRNA which encodes the minor capsid polypeptide sigma Ia and the nonstructural polypeptide sigma IbNS. Biochem Biophys Res Commun 1986, I40:508-5 I4.

26. Dryden KA, Coombs KM, Yeager M: The structure of orthoreoviruses. In Segmented Double-stranded RNA Viruses: Structure and Molecular Biology Edited by: Patton IT. Horizon Press; 2008:3-25.

27. Schiff LA, Nibert ML, Co MS, Brown EG, Fields BN: Distinct binding sites for zinc and double-stranded RNA in the reovirus outer capsid protein sigma 3. Mol Cell Biol 1988, 8:273-283.

28. Gonzalez-Lopez C, Martinez-Costas J, Esteban M, Benavente J: Evidence that avian reovirus sigmaA protein is an inhibitor of the double-stranded RNA-dependent protein kinase. J Gen Virol 2003, 84:1629-1639.

29. Yin HS, Su YP, Lee LH: Evidence of nucleotidyl phosphatase activity associated with core protein sigma $A$ of avian reovirus SI I33. Virology 2002, 293:379-385.

30. Noble $S$, Nibert ML: Core protein mu2 is a second determinant of nucleoside triphosphatase activities by reovirus cores. J Virol 1997, 71:7728-7735.

31. Bisaillon M, Bergeron J, Lemay G: Characterization of the nucleoside triphosphate phosphohydrolase and helicase activities of the reovirus lambdal protein. I Biol Chem 1997, 272: $18298-18303$

32. Wiener JR, Bartlett JA, Joklik WK: The sequences of reovirus serotype 3 genome segments $M I$ and $M 3$ encoding the minor protein mu 2 and the major nonstructural protein mu NS, respectively. Virology 1989, 169:293-304.

33. Breun LA, Broering TJ, McCutcheon AM, Harrison SJ, Luongo CL, Nibert ML: Mammalian reovirus $L 2$ gene and lambda2 core spike protein sequences and whole-genome comparisons of reoviruses type I Lang, type 2 Jones, and type 3 Dearing. Virology 2001, 287:333-348.

34. Yin P, Keirstead ND, Broering TJ, Arnold MM, Parker JSL, Nibert ML, et al.: Comparisons of the MI genome segments and encoded $\mu 2$ proteins of different reovirus isolates. Virol J I(6):.

35. Chiu C], Lee LH: Cloning and nucleotide sequencing of the S4 genome segment of avian reovirus SII33. Arch Virol 1997, 1 42:25 15-2520.

36. Duncan R: Extensive sequence divergence and phylogenetic relationships between the fusogenic and nonfusogenic orthoreoviruses: a species proposal. Virology 1999 260:316-328.

37. Liu HJ, Huang PH: Sequence and phylogenetic analysis of the sigma A-encoding gene of avian reovirus. J Virol Meth 200I, 98:99-107.

38. Kapczynski DR, Sellers HS, Simmons V, Schultz-Cherry S: Sequence analysis of the $\mathbf{S 3}$ gene from a turkey reovirus. Virus Genes 2002, 25:95-100.

39. Sellers HS, Linnemann EG, Pereira L, Kapczynski DR: Phylogenetic analysis of the sigma 2 protein gene of turkey reoviruses. Avian Dis 2004, 48:65I-657.

40. Touris-Otero F, Cortez-San Martín M, Martinez-Costas J, Benavente $\mathrm{J}$ : Avian reovirus morphogenesis occurs within viral factories and begins with the selective recruitment of sigma NS and lambda A to mu NS inclusions. J Mol Biol 2004, 34 I:36 I-374.

41. Noad L, Shou JY, Coombs KM, Duncan R: Sequences of avian reovirus $M 1, M 2$ and $M 3$ genes and predicted structure/function of the encoded mu proteins. Virus Research 2006, I l 6:45-57.
42. Hsiao J, Martinez-Costas J, Benavente J, Vakharia VN: Cloning, expression, and characterization of avian reovirus guanylyltransferase. Virology 2002, 296:288-299.

43. Shen PC, Chiou YF, Liu HJ, Song CH, Su YP, Lee LH: Genetic variation of the lambda $\mathbf{A}$ and lambda $\mathbf{C}$ protein encoding genes of avian reoviruses. Res Vet Sci 2007, 83:394-402.

44. Patrick M, Duncan R, Coombs KM: Generation and genetic characterization of avian reovirus temperature-sensitive mutants. Virology 200I, 284: II3-I22.

45. Sambrook J, Fritsch EF, Maniatis T: Molecular cloning: a laboratory manual 2nd edition. Cold Spring Harbor: Cold Spring Harbor Laboratory; 1989.

46. Wilbur WJ, Lipman DJ: Rapid Similarity Searches of NucleicAcid and Protein Data Banks. Proc Natl Acad Sci (USA) 1983, 80:726-730.

47. Martinez HM: An Efficient Method for Finding Repeats in Molecular Sequences. Nucl Acids Res 1983, I I:4629-4634.

48. Lipman DJ, Pearson WR: Rapid and Sensitive Protein Similarity Searches. Science 1985, 227:|435-|44|.

49. Thompson JD, Higgins DG, Gibson TJ: CLUSTAL W: Improving the sensitivity of progressive multiple sequence alignment through sequence weighting, position-specific gap penalties and weight matrix choice. Nucleic Acids Res 1994, 22:4673-4680.

50. Notredame C, Higgins DG, Heringa J: T-Coffee: A novel method for fast and accurate multiple sequence alignment. J Mol Biol 2000, 302:205-217

5I. Tamura K, Dudley J, Nei M, Kumar S: MEGA4: Molecular evolutionary genetics analysis (MEGA) software version 4.0. Mol Biol Evol 2007, 24:1596-1599.

52. Tao Y, Farsetta DL, Nibert ML, Harrison SC: RNA synthesis in a cage - Structural studies of reovirus polymerase lambda3. Cell 2002, I I I:733-745.

53. Pettersen EF, Goddard TD, Huang CC, Couch GS, Greenblatt DM, Meng EC, et al: UCSF chimera - A visualization system for exploratory research and analysis. J Comput Chem 2004, 25:1605-1612.

54. Starnes MC, Joklik WK: Reovirus protein lambda 3 is a poly(C)dependent poly(G) polymerase. Virology 1993, I93:356-366.

55. Fang Q, Attoui H, Cantaloube JF, Biagini P, Zhu Z, de Micco P, et al: Sequence of genome segments $I, 2$, and 3 of the grass carp reovirus (Genus Aquareovirus, family Reoviridae). Biochem Biophys Res Commun 2000, 274:762-766.

56. Bisaillon $M$, Lemay $G$ : Computational sequence analysis of mammalian reovirus proteins. Virus Genes I999, I 8:13-37.

57. Morozov SY: A possible relationship of reovirus putative RNA polymerase to polymerases of positive-strand RNA viruses. Nucleic Acids Res 1989, I 7:5394.

58. Bruenn JA: Relationships Among the Positive Strand and Double-Strand Rna Viruses As Viewed Through Their RnaDependent Rna-Polymerases. Nucl Acids Res 1991, 19:217-226.

59. Bruenn JA: A structural and primary sequence comparison of the viral RNA-dependent RNA polymerases. Nucl Acids Res 2003, 31: |82|-|829.

60. Kim J, Tao Y, Reinisch KM, Harrison SC, Nibert ML: Orthoreovirus and Aquareovirus core proteins: conserved enzymatic surfaces, but not protein-protein interfaces. Virus Research 2004, I0I:I5-28.

61. Guardado-Calvo P, Vazquez-Iglesias L, Martinez-Costas J, Llamas-Saiz AL, Schoehn G, Fox GC, et al.: Crystal structure of the avian reovirus inner capsid protein sigmaA. J Virol 2008, 82: I I 208-I I 2 I6.

62. Zhang X, Walker SB, Chipman PR, Nibert ML, Baker TS: Reovirus polymerase lambda 3 localized by cryo-electron microscopy of virions at a resolution of $\mathbf{7 . 6}$ angstrom. Nature Structural Biology 2003, 10:1011-1018. 